\title{
Simultaneous Quantitative Assessment of Ochratoxin A, Patulin, 5-Hydroxymethylfurfural, and Bisphenol A in Fruit Drinks Using HPLC with Diode Array-Fluorimetric Detection
}

\author{
Norfarizah Hanim Hassan ${ }^{1}$, Haneen Ibrahim Ahmad Al Othman ${ }^{1}$, \\ Nur Rabiatutadawiah Abdul Malek ${ }^{1}$, Musfirah Zulkurnain ${ }^{2}$ D, \\ Bahruddin Saad ${ }^{3}$ and Yong Foo Wong ${ }^{1, *(D)}$ \\ 1 School of Chemical Sciences, Universiti Sains Malaysia, Penang 11800, Malaysia; \\ norfarizahhassan@gmail.com (N.H.H.); alothmanhanin@gmail.com (H.I.A.A.O.); \\ tadakmph@gmail.com (N.R.A.M.) \\ 2 Food Technology Division, School of Industrial Technology, Universiti Sains Malaysia, \\ Penang 11800, Malaysia; musfirah.z@usm.my \\ 3 Fundamental and Applied Sciences Department, Universiti Teknologi PETRONAS, Seri Iskandar, \\ Perak 32610, Malaysia; bahrudsaad@gmail.com \\ * Correspondence: wongyongfoo@usm.my; Tel.: +60-4653-403-1; Fax: +60-4657-485-4
}

Received: 28 September 2020; Accepted: 31 October 2020; Published: 9 November 2020

\begin{abstract}
The analysis of regulated contaminants in fruit drinks often requires suitable validated and rapid analytical methods for cost-effective food control, and is of considerable interest among the fruit beverage industry. This study demonstrated a rapid and sensitive high-performance liquid chromatography approach for the simultaneous determination of ochratoxin A (OTA), patulin (PAT), 5-hydroxymethylfurfural (HMF), and bisphenol A (BPA) in various fruit drinks. The separations were achieved using a C18 core-shell column with both photo-diode array and fluorimetric detections connected in series. A gradient system consisting of methanol and $0.1 \%$ formic acid at a flow rate of $1.2 \mathrm{~mL} \mathrm{~min}^{-1}$, thermostated at $35^{\circ} \mathrm{C}$, provided fast elution with run time $<9 \mathrm{~min}$. Sample pretreatment was optimised to enable extraction of all analytes from fruit drink matrices. The optimised method was validated. Correlation coefficients of $R>0.99$ were achieved with detection limits of $0.5 \mathrm{ng} \mathrm{mL}^{-1}$ (OTA), $1.1 \mathrm{ng} \mathrm{mL}^{-1}$ (PAT), $7.9 \mathrm{ng} \mathrm{mL}^{-1}$ (HMF), and $1.0 \mathrm{ng} \mathrm{mL}^{-1}$ (BPA). Recoveries ranged from $82 \%$ to $99 \%$. Good relative standard deviations for intraday retention times $(\leq 3.54 \%)$ and peak area $(\leq 3.5 \%)$ were achieved. The developed multi-contaminants analysis method was successfully applied to determine OTA, PAT, HMF, and BPA in various fruit drinks.
\end{abstract}

Keywords: high-performance liquid chromatography; core-shell column; mycotoxins; hydroxymethylfurfural; bisphenol A; fruit juice; fruit drinks

\section{Introduction}

In recent years, the fast pace of modern lifestyles has led to changes in the consumers' behavioural patterns in food preparation, consumption habits, and daily food intake to maintain a balanced and healthy diet. In particular, ready-to-drink pre-packaged fruit drinks have risen as a popular source of convenient and healthy beverage globally. Projections have indicated that the global fruit juices market will reach a volume of 50.6 billion litres by 2024 [1]. However, the growth of the markets has also raised food safety concerns among consumers on the possible exposure to contaminants, especially mycotoxins, endocrine-disrupting chemicals, and others [2]. The risk of such exposure 
is normally associated with possible production of contaminants during fruit storage, processing, and packaging $[3,4]$.

Mycotoxins are secondary metabolites naturally produced by certain types of microfungi or moulds. Acute consumption of these food-borne toxic compounds can cause severe illness and deaths in humans and animals. To date, several hundred mycotoxins have been identified, but the most commonly observed mycotoxins in fruits that present a concern to human health include ochratoxin A (OTA) and patulin (PAT). OTA (Figure 1A) is produced mainly by moulds from the genera Aspergillus and Penicillium, and commonly occur and distribute in several food products, including cereals, coffee beans, spices, dried fruits, grape juice, and others [5]. Tropical or subtropical regions with warm and humid climates are highly susceptible to OTA contaminations as a consequence of fungal growth [6]. Biologically, OTA displays hepatotoxic, teratogenic, carcinogenic, and immunosuppressive properties. Due to its chronic toxicity, the International Agency for Research on Cancer (IARC) has classified OTA as Group 2B (i.e., a possible human carcinogenic substance) [7]. As OTA is relatively stable, the Joint FAO/WHO Expert Committee on Food Additives (JECFA) has approved a provisional tolerable weekly intake for OTA of $100 \mathrm{ng} \mathrm{kg}^{-1} \mathrm{bw}_{\text {week }}{ }^{-1}$, while the European Union Commission (EU) has established $2 \mu \mathrm{g} \mathrm{kg}^{-1}$ as the maximum permissible limits in grape juice, grape nectar, and its concentrates $[8,9]$.<smiles>C[C@H]1Cc2c(Cl)cc(C(=O)N[C@@H](Cc3ccccc3)C(=O)O)c(O)c2C(=O)O1</smiles>

$$
\begin{aligned}
& \text { Ochratoxin } \mathbf{A}, \mathrm{C}_{20} \mathrm{H}_{18} \mathrm{ClNO}_{6} \\
& \mathbf{M W}=403 \text { gmol }^{-1}
\end{aligned}
$$

(C)

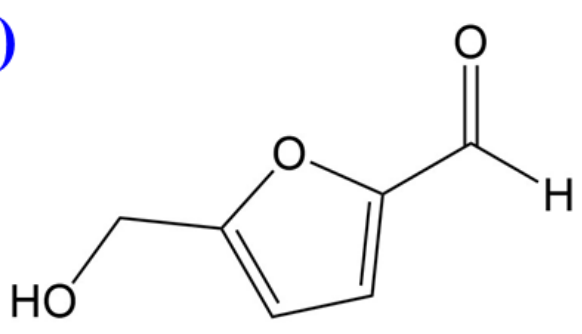

5-hydroxymethylfurfural, $\mathrm{C}_{6} \mathrm{H}_{6} \mathrm{O}_{3}$ $\mathbf{M W}=126 \mathrm{gmol}^{-1}$
(B)<smiles>O=C1C=C2C(=CCOC2O)O1</smiles>

Patulin, $\mathrm{C}_{7} \mathrm{H}_{6} \mathrm{O}_{4}$ $\mathbf{M W}=154 \mathrm{gmol}^{-1}$

Figure 1. Molecular representation and molecular weight (MW) of (A) ochratoxin A (OTA); (B) patulin (PAT); (C) 5-hydroxymethylfurfural (HMF); (D) bisphenol A (BPA).

Besides OTA, patulin (PAT; Figure 1B), an unsaturated heterocyclic lactone, is one of the most studied mycotoxins in fruits and their processed products. PAT has been identified as a major causative agent of postharvest decay which is produced by a few species of fungi, including Aspergillus, Byssochlamys, Gymnoascus, Paecilomyces, and Penicillium [10,11]. These microfungi can be found in apples, apricots, peaches, oranges, tomatoes, and a range of their processed products. A few Penicillium spp. can grow even at below $5{ }^{\circ} \mathrm{C}$, and the produced PAT is able to withstand thermal 
processing during the pasteurization process [11,12]. Clinically, PAT is known to exhibit genotoxic, immunotoxic, neurotoxic, teratogenic, and mutagenic properties, while acute PAT toxicity symptoms for humans include nausea, gastrointestinal disturbance, vomiting, and kidney failure [13-15]. Due to the evidence of its potential toxicity properties, the JECFA has suggested the provisional maximum tolerable daily intake for PAT of $0.2 \mu \mathrm{g} \mathrm{kg}^{-1} \mathrm{bw}_{\text {day }}{ }^{-1}$ for young children and $0.4 \mu \mathrm{g} \mathrm{kg}^{-1} \mathrm{bw}_{\text {day }}{ }^{-1}$ for adults [16]. The EU has regulated maximum permissible PAT levels in fruit juices, nectars, apple wine, and other fermented apple drinks at $50 \mu \mathrm{g} \mathrm{kg}^{-1}$, whilst the maximum level was set at $25 \mu \mathrm{g} \mathrm{kg}^{-1}$ in other solid apple products and $10 \mu \mathrm{g} \mathrm{kg}^{-1}$ for apple products for infants and young children [8].

In order to reduce the levels of mycotoxins and prolong the shelf life of the fruit drinks, thermal treatments are often applied during the manufacturing processes. However, such heating processes also promote the occurrence of non-enzymatic browning reactions (Maillard reactions and caramelisation), which mainly produce neo-formed contaminations, such as furan, 5-hydroxymethylfurfural (HMF; Figure 1C), and others. These by-products, particularly HMF (5-(hydroxymethyl) furan-2-carbaldehyde), have gained much interest due to their high toxicological potential to human. As fruit drinks contain a high level of carbohydrates, HMF can be developed during the heating process or prolonged storage $[17,18]$. The International Federation of Fruit Juice Processors (IFFJP) has suggested that the maximum level for HMF in fruit juice is $5-10 \mathrm{mg} \mathrm{L}^{-1}$ and $25 \mathrm{mg} \mathrm{L}^{-1}$ for fruit concentrates [19]. The EU and the Codex Alimentarius have established a maximum of $20 \mathrm{mg} \mathrm{kg}^{-1} \mathrm{HMF}$ for juices made for children and $50 \mathrm{mg} \mathrm{kg}^{-1}$ in apple juice [20].

Apart from mycotoxins and furfurals, bisphenol A (BPA; Figure 1D) is another contaminant which is normally found in plastic-based packaging materials. BPA has been used industrially as the precursor to produce polycarbonate plastics which are widely used as packaging for food products. However, the polymer coating of the packaging can undergo polycarbonate hydrolysis, causing the leaching of BPA into the packaged food or fruits beverages. Studies have highlighted that the major BPA exposure pathway for human is through ingestion from contaminated food products [21]. Clinically, BPA has been identified as an endocrine disruptor which causes hormone imbalance in humans and could potentially disrupt major metabolic pathways [21-23]. Consumption of high doses of BPA may cause organ failure, leukaemia, and severe weight loss [22]. Previously, the European Food Safety Authority (EFSA) had recommended a tolerable daily intake of BPA of $50 \mathrm{\mu g} \mathrm{kg}^{-1} \mathrm{bw} /$ day, however, due to the threat imposed by BPA exposure, it has been reduced to $4 \mu \mathrm{g} \mathrm{kg}^{-1}$ bw day ${ }^{-1}$ [24]. According to human BPA exposure data from a urinary BPA study conducted across seven Asian countries, the presence of BPA was found in $~ 94 \%$ of the analysed urine samples (concentration levels of $<0.2-30.1 \mathrm{ng} \mathrm{mL}^{-1}$ ) [25].

Considering their potential occurrence in fruit drinks, various analytical approaches that include both sample preparation and chromatographic separation have been reported for the quantitation of OTA, PAT, HMF, and BPA either separately or in combinations. Due to the non-volatile nature of these compounds, liquid chromatography with different detection techniques has been the preferred method for their assessments. For gas chromatographic analyses, a derivatisation process is mandatory to improve the low volatility of these compounds. Although many methods have been developed for the determination of these food contaminants, studies on the simultaneous determination of OTA, PAT, HMF, and BPA have not been reported. In this paper, an improved HPLC-UV/FL method for the simultaneous extraction, separation, and quantification of these compounds in complex fruit beverages and drinks matrices are described. The method was validated, and its analytical practicality was demonstrated in the determination of these contaminants in different types of fruit drinks, including fruit juices and fruit concentrates commercially marketed in Malaysia.

\section{Materials and Methods}

\subsection{Chemicals and Reagents}

Patulin (PAT; $\geq 97 \%$ ) was purchased from Romer Labs Diagnostic GmbH (Tulln, Austria). Bisphenol A (BPA; $\geq 99 \%$; Toronto Research Chemicals Inc., North York, Ontario, Canada) was 
provided by Dr. Noorfatimah Binti Yahaya (Advanced Medical and Dental Institute, Penang, Malaysia). Ochratoxin A (OTA; $\geq 98 \%$ ), 5-hydroxymethylfurfural (HMF; $\geq 99 \%$ ), formic acid, Carrez I, potassium hexacyanoferrate (III) $(\sim 99 \%)$, and Carrez II, zinc acetate dihydrate $(\geq 98 \%)$ were purchased from Sigma-Aldrich (St. Louis, MO, USA). HPLC grade acetonitrile (ACN) and ethyl acetate (EA) were purchased from Elite Advanced Materials Sdn. Bhd. (Selangor, Malaysia). Methanol (HPLC grade) was purchased from Fisher Scientific (Waltham, MA, USA). Chloroform was supplied by Merck (Darmstadt, Germany). Ultrapure water (resistivity: $18.2 \mathrm{M} \Omega \mathrm{cm}^{-1}$ ) was produced using a Milli-Q system (Millipore, Burlington, MA, USA) and was used throughout the study. A nylon membrane filter $(0.45 \mu \mathrm{m})$ was purchased from LabServ Sdn Bhd (Selangor, Malaysia). Sodium hydroxide pellets were obtained from Bendosen Laboratory Chemicals (Bendosen, Norway).

\subsection{Fruit Beverage Samples}

A total of 14 commercial fruit drinks and concentrates were randomly collected from local supermarkets in Penang, Malaysia. The samples collected included ambarella, apple, dates, grapes, guava, kiwi, lychee, mixed fruit, nutmeg, pineapple, plum (two samples), roselle, and soursop.

\subsection{High-Performance Liquid Chromatographic System}

Separation and quantification of analytes were carried out using the HPLC system (model 2695) from Waters Alliance (Waters Corporation; Milford, MA, USA). The instrument was equipped with a Waters (model 2998) photodiode array detector (PDA), a Waters (model 2475) multi $\lambda$ fluorescence detector (FL), and an autosampler. The system was also equipped with an online degasser and a column oven. The PDA detector was configured at $284 \mathrm{~nm}$ and $276 \mathrm{~nm}$ to detect and quantify HMF and PAT, respectively. For fluorescence detection, BPA and OTA were identified and quantified using wavelengths of $275 \mathrm{~nm}$ (excitation) and $300 \mathrm{~nm}$ (emission), and $333 \mathrm{~nm}$ (excitation), and $443 \mathrm{~nm}$ (emission), respectively. The chromatographic separation was carried out using a solid core Kinetex ${ }^{\circledR}$ EVO C18 column ( $150 \mathrm{~cm} \times 4.6 \mathrm{~mm}$ i.d., $5 \mu \mathrm{m}$ particle size; Phenomenex, CA, USA). The study was carried out in gradient-elution mode. The initial mobile phase was composed of methanol and acidified water (formic acid $(0.1 \% v / v)$ ) (18:82), retaining composition for $2 \mathrm{~min}$, changed from $18 \%$ to $95 \%$ methanol at $8 \mathrm{~min}$ (retained $95 \% \mathrm{MeOH}$ for $2 \mathrm{~min}$ ) and lowered to $18 \%$ at $10.5 \mathrm{~min}$ (held for $2 \mathrm{~min}$ ) with a flow rate of $1.2 \mathrm{~mL} \mathrm{~min}^{-1}$. The volume of the injected sample was $20 \mu \mathrm{L}$, and the column temperature was set at $35^{\circ} \mathrm{C}$.

\subsection{Stock and Standard Solutions}

Stock solutions of HMF $\left(2000 \mu \mathrm{g} \mathrm{mL}^{-1}\right)$, OTA $\left(19.6 \mu \mathrm{g} \mathrm{mL} \mathrm{L}^{-1}\right)$, and PAT $\left(4 \mu \mathrm{g} \mathrm{mL} \mathrm{L}^{-1}\right)$ were prepared in ultrapure water. BPA stock solution $\left(1000 \mu \mathrm{g} \mathrm{mL} \mathrm{m}^{-1}\right)$ was prepared with ultrapure water and acetonitrile with a ratio of 60:40, respectively. The individual stock standard solutions were sonicated and stored $\left(4{ }^{\circ} \mathrm{C}\right)$. Standard solutions for the calibration curves were prepared by the appropriate dilution of the stock solutions with ultrapure water.

\subsection{Preparation of Fruit Drink Samples}

A miniaturised liquid-liquid extraction procedure with some modifications was employed [26,27]. The first clean-up method involved the addition of Carrez I $\left(0.451 \mathrm{~mol} \mathrm{~L}^{-1}\right)$ and Carrez II $\left(1.339 \mathrm{~mol} \mathrm{~L}^{-1}\right)$ solutions $(500 \mu \mathrm{L})$ to the fruit drink sample $(40 \mathrm{~mL})$, followed by centrifugation. For fruit concentrates, appropriate dilution was made when the concentration of the analytes exceeded the linear ranges. The precipitate was then separated by decantation and the $\mathrm{pH}$ of resulting sample solutions was adjusted to $\mathrm{pH} \sim 8$ using $5 \mathrm{M} \mathrm{NaOH}$ to eliminate excess $\mathrm{Zn}$ ions as $\mathrm{Zn}(\mathrm{OH})_{2}$. Prior to extraction, the purified sample was stored in a refrigerator $\left(4{ }^{\circ} \mathrm{C}\right)$. All the samples $(1 \mathrm{~mL})$ were extracted twice using $\mathrm{CHCl}_{3}$ $(1 \mathrm{~mL})$ with vortexing $(6 \mathrm{~min})$, and the remaining water phase was subjected to additional extraction using $1 \mathrm{~mL}$ of ethyl acetate. The resulting organic phases were then evaporated to dryness under a gentle flow of nitrogen. The dried residue was immediately reconstituted in $400 \mu \mathrm{L}$ of $\mathrm{MeOH}$ :water 
$(30: 70 ; v / v)$ mixture and syringe filtered with a $0.45-\mu \mathrm{m}$ nylon membrane filter. The filtered solution was directly injected into the HPLC-UV/FL system.

\subsection{Method Validation}

Method validation parameters (linearity, limit of detection (LOD), limits of quantification (LOQ), repeatability, and recovery) were investigated. The linearity was investigated over the range of $0.5-50.0 \mathrm{ng} \mathrm{mL}^{-1}$ (OTA), 10-200 $\mathrm{ng} \mathrm{mL}^{-1}$ (PAT), 10-1000 $\mathrm{ng} \mathrm{mL}^{-1}$ (HMF), and 1-100 $\mathrm{ng} \mathrm{mL}^{-1}$ (BPA). LOD values were estimated at an $\mathrm{S} / \mathrm{N}$ ratio of 3.3, whereas LOQ was estimated at an $\mathrm{S} / \mathrm{N}$ of 10 . Intra-day precision was studied by analysing standard mixtures of OTA $\left(2,20\right.$, and $\left.40 \mathrm{ng} \mathrm{mL}^{-1}\right)$, PAT $\left(20,60\right.$, and $\left.150 \mathrm{ng} \mathrm{mL}^{-1}\right), \operatorname{HMF}\left(40,400\right.$, and $\left.800 \mathrm{ng} \mathrm{mL}^{-1}\right)$, and BPA $\left(5,40\right.$, and $\left.80 \mathrm{ng} \mathrm{mL}^{-1}\right)$ at three concentration levels, on the same day. The obtained results were expressed as relative standard deviation (\% RSD). The recovery test was performed by spiking three concentration levels for OTA, PAT, HMF, and BPA at different spiked ranges; low concentration (2-20 $\left.\mathrm{ng} \mathrm{mL}^{-1}\right)$, mid concentration (20-400 $\left.\mathrm{ng} \mathrm{mL}^{-1}\right)$, and high concentration $\left(45-800 \mathrm{ng} \mathrm{mL}^{-1}\right)$ into a selected fruit drink sample.

\subsection{Data Handling}

Data acquisition and processing were performed using Empower 2 software (Waters Corporation, Milford, MA, USA). Acquired Empower 2 data were exported in CSV file format, followed by reconstruction using OriginPro 8 SR4 V8.0951 (B951) software (Origin, Northampton, MA, USA) to generate the chromatograms. Statistical analyses were performed using Microsoft Excel Version 2002 (Build 12527.21104; Microsoft Corporation, Redmond, WA, USA).

\section{Results and Discussion}

\subsection{HPLC-DAD/FL Method Development}

In the present work, an octadecyl silane (C18) core-shell column, which provides better chromatographic efficiency and generates flatter van Deemter curves compared to the C18 column packed with fully-porous particles, was chosen to effect the appropriate chromatographic separations [28]. The influences of chromatographic variables on solutes retention and separation were studied. Initially, the effect of different ratios of water $(0-100 \%)$ and methanol $(0-100 \%)$ or acetonitrile (0-100\%) as mobile phases for the separation of OTA, PAT, HMF, and BPA were investigated. Results indicated that a composition of $\mathrm{MeOH}: \mathrm{H}_{2} \mathrm{O}(18: 82, v / v \%)$ provided good resolution of the analytes. However, the analysis time was relatively long ( $>30 \mathrm{~min}$ ) due to the late elution of BPA and OTA. To further shorten the analysis time, a gradient elution approach was initiated using $18 \% \mathrm{MeOH}$ (held for $2 \mathrm{~min}$; to promote separation of PAT and HMF), which progressively ramped to $95 \% \mathrm{MeOH}$ (held for $6 \mathrm{~min}$; to resolve OTA and BPA), then returned to $18 \% \mathrm{MeOH}$ and equilibrated for $2 \mathrm{~min}$. As OTA is a weak acid (pKa value 4.4), the mobile phases were added with formic acid $(0.1 \% v / v)$ to prevent potential peak tailing and unspecific adsorption to the C18 column [29]. Good efficiency and shorter analysis time (by $\sim 70 \%$ ) were achieved by applying the gradient elution at a flow rate of

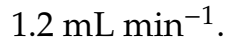

Theoretically, elevated column temperature can reduce the viscosity of the mobile phase and increase the diffusion coefficient and mass transfer, which subsequently reduce peak broadening. Thus, the effect of column temperature was investigated. Excellent separation efficiency and the shortest analysis time were obtained when the column was thermostated at $35^{\circ} \mathrm{C}$, yielding narrow peaks with an average peak width at base $\left(w_{\mathrm{b}}\right)$ of $\sim 0.24 \mathrm{~min}$. The effects of injection volume were investigated to improve the sensitivity without significant loss of resolution. Higher injection volumes yielded larger peak heights and areas, which translated to better sensitivity. However, peak widths also increased with the increase of the injection volume. Taking into account the peak shapes and band broadening, injection volume of $20 \mu \mathrm{L}$ was selected. 
Although a fluorescence detector is many folds more sensitive than UV, the PAT and HMF exhibited weak fluorescence properties, and displayed strong UV absorption. Thus, absorbance wavelength at $276 \mathrm{~nm}$ and $284 \mathrm{~nm}$ was selected for PAT and HMF, respectively, for detection and quantification. OTA and BPA are fluorophores that displayed strong fluorescence properties; therefore, fluorescence detection was applied. Excitation and emission wavelengths were briefly optimised to obtain maximum responses for OTA and BPA. The chromatographic effluents were subjected to both photo-diode array (PDA) and fluorimetric (FL) detections that were connected in series to enable sensitive detection of all the analytes of interest. The adopted HPLC-DAD/FL conditions are summarised in Table 1, whilst Figure 2 shows typical chromatograms of the OTA, PAT, HMF, and BPA operated under the optimised conditions. The developed multi-contaminants analysis approach achieved separation of all solutes in less than $9 \mathrm{~min}$, which is much shorter than some of the reported chromatographic approaches $[12,19,30]$. To date, this is the first report on the simultaneous separation and detection of OTA, PAT, HMF, and BPA in a single analysis.

Table 1. Adopted HPLC operating conditions for simultaneous detection of 5-hydroxymethylfurfural (HMF), patulin (PAT), ochratoxin (OTA), and bisphenol A (BPA) using photo-diode array (PDA) and fluorimetric (FL) detectors.

\begin{tabular}{lll}
\hline Adopted HPLC Conditions & & \\
\hline Variable & Optimum Value & \\
\hline Flow rate & $1.2 \mathrm{~mL} \mathrm{~min}^{-1}$ & \\
Temperature & $35^{\circ} \mathrm{C}$ & \\
Initial mobile phase composition (\%) & $\mathrm{MeOH}$ : Acidified water (18:82) & \\
& $0-2.0 \mathrm{~min}$ & $(18 \%)$ \\
Gradient programming & $2.0-8.0 \mathrm{~min}$ & $(95 \%)$ \\
(Methanol composition, $\%)$ & $8.0-10 \mathrm{~min}$ & $(95 \%)$ \\
& $10-10.5 \mathrm{~min}$ & $(18 \%)$ \\
Injection volume & $10.5-12.5 \mathrm{~min}$ & $(18 \%)$ \\
PDA configuration & $20 \mu \mathrm{L}$ & $284 \mathrm{~nm}$ \\
& $\mathrm{HMF}{ }^{1}$ & $276 \mathrm{~nm}$ \\
FL configuration & $\mathrm{PAT}^{2}$ & $275 \mathrm{~nm}$ (excitation), $300 \mathrm{~nm}$ (emission) \\
& $\mathrm{BPA}^{3}$ & $333 \mathrm{~nm}$ (excitation), $443 \mathrm{~nm}$ (emission) \\
\hline
\end{tabular}

${ }^{1}$ HMF: 5-hydroxymethylfurfural; ${ }^{2}$ PAT: patulin; ${ }^{3}$ BPA: bisphenol A; ${ }^{4}$ OTA: ochratoxin A.
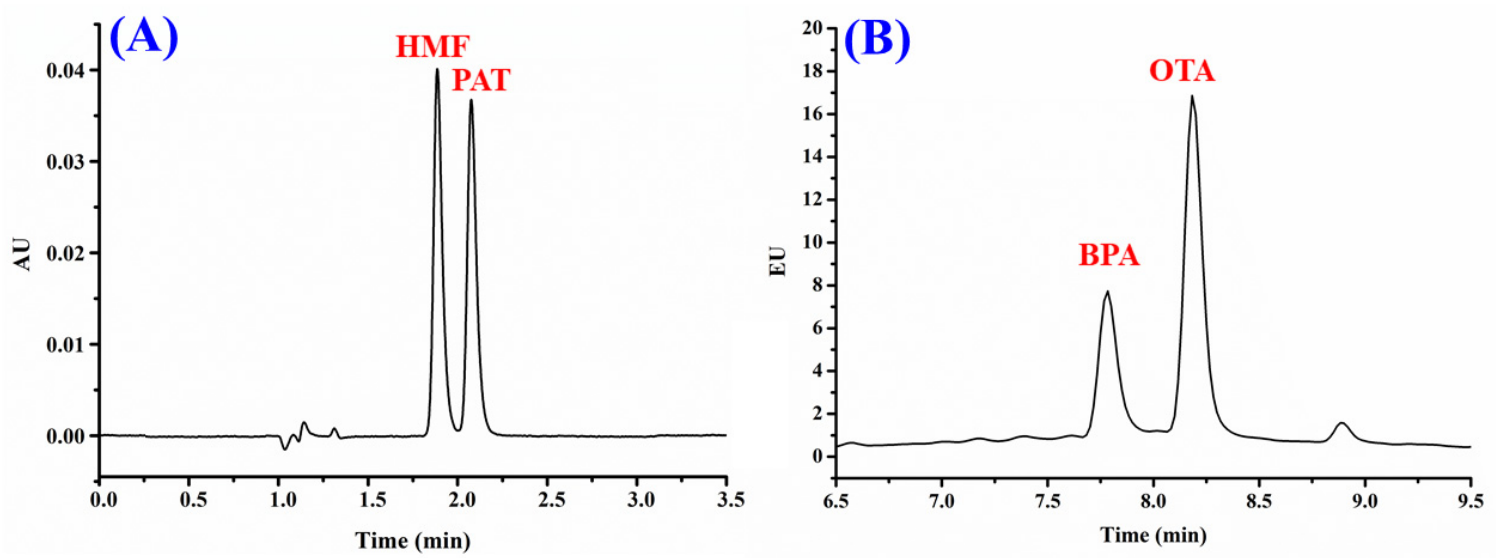

Figure 2. Typical chromatogram obtained from the introduction of standards mixture containing (A) 5-hydroxymethylfurfural (HMF; $100 \mathrm{ng} \mathrm{mL}^{-1}$ ) and patulin (PAT; $150 \mathrm{ng} \mathrm{mL}^{-1}$ ) using a photo-diode array detector; (B) bisphenol A (BPA; $20 \mathrm{ng} \mathrm{mL}^{-1}$ ) and ochratoxin (OTA; $45 \mathrm{ng} \mathrm{mL}^{-1}$ ) using a fluorimetric (FL) detector. 


\subsection{Optimisation of Clean-Up and Preconcentration Strategies}

The inherent complexity of fruit drinks and low levels of the analytes limits the direct analysis of the samples. Relatively high sugar (glucose, sucrose, xylose, and fructose) content in the fruit drinks also makes direct chromatographic analyses not possible [15]. Therefore, clean-up and preconcentration steps are required to overcome these problems. The first clean-up procedure involved the addition of Carrez solutions (a mixture of potassium hexacyanoferrate (III) and zinc acetate dihydrate) to the sample solutions followed by centrifugation to provide clarification effects. The precipitate was removed, and the $\mathrm{pH}$ of resulting sample solutions was adjusted to $\mathrm{pH} \sim 8$ to remove excess $\mathrm{Zn}$ ions. The clarified solution was extracted separately using $\mathrm{CHCl}_{3}$ (to recover OTA, HMF, and BPA) and EA (to recover PAT) with vortexing, and the organic phases were collected and evaporated to dryness under a gentle stream of nitrogen. The dried residue was immediately reconstituted with $400 \mu \mathrm{L}$ of $\mathrm{MeOH}$ :water $(30: 70 ; v / v)$ and filtered before injection. By using such clean-up approaches, interfering components are greatly reduced, which allows selective extraction of the targeted analytes.

\subsection{Method Validation}

\subsubsection{Linearity}

A series of standard working solutions were prepared, extracted, and analysed under the optimised conditions outlined in Sections 2.3 and 2.5. The maximum permitted level of each analytes was taken into consideration while selecting the concentration ranges for all the analytes. The regression equations and correlation coefficients are summarised in Table 2. Excellent linearities were achieved for all of the four analytes, with a correlation coefficient of $R>0.99$.

Table 2. Calibration curves, limits of detection (LOD), and limits of quantification (LOQ) for ochratoxin A (OTA), patulin (PAT), 5-hydroxymethylfurfural (HMF), and bisphenol A (BPA) using the optimised HPLC-PDA/FL method.

\begin{tabular}{|c|c|c|c|c|c|}
\hline Analytes & $\begin{array}{l}\text { Linear Range } \\
\left.\text { (ng } \mathrm{mL}^{-1}\right)\end{array}$ & $\begin{array}{c}\text { Regression } \\
\text { Equation }\end{array}$ & Linearity, $r^{2}$ & LOD $\left(\mathrm{ng} \mathrm{mL} \mathrm{m}^{-1}\right)$ & LOQ (ng mL $\left.\mathrm{mL}^{-1}\right)$ \\
\hline OTA $^{1}$ & $0.5-50$ & $y=4629.4 x+5522.6$ & 0.9984 & 0.5 & 1.7 \\
\hline PAT $^{2}$ & $10-200$ & $y=77.499 x-57.109$ & 0.9998 & 1.1 & 3.4 \\
\hline $\mathrm{HMF}^{3}$ & $10-1000$ & $y=302.62 x-2243.6$ & 0.9993 & 7.9 & 24.0 \\
\hline BPA $^{4}$ & $1-100$ & $y=8820.4 x+115511$ & 0.9988 & 1.0 & 3.2 \\
\hline
\end{tabular}

\subsubsection{Limits of Detection and Quantitation}

The LODs were determined with a signal to noise ratio of 3.3, whereas LOQs were calculated with a signal to noise ratio of 10. Relatively low LODs and LOQs were obtained for all analytes, as shown in Table 2. The LOD values obtained were $0.5 \mathrm{ng} \mathrm{mL}-1,1.1 \mathrm{ng} \mathrm{mL}-1,7.9 \mu \mathrm{g} \mathrm{mL}^{-1}$, and $1.0 \mathrm{ng} \mathrm{mL}^{-1}$ for OTA, PAT, HMF, and BPA, respectively. Overall, the achieved sensitivities meet the requirements for the assessment of these contaminants in the fruit drinks, with maximum permitted concentrations as defined by the European Union Commission and Codex Alimentarius. Interestingly, the developed HPLC-UV/FL method exhibited significantly lower LOD values for OTA $\left(0.5 \mathrm{ng} \mathrm{mL}^{-1}\right)$ and BPA (1.0 $\left.\mathrm{ng} \mathrm{mL}^{-1}\right)$ compared to other reported methods using CE-PDA (OTA, $11.2 \mathrm{ng} \mathrm{mL}^{-1}$; BPA, $55 \mu \mathrm{g} \mathrm{L}^{-1}$ ) [31,32], and GC-MS (BPA, $20 \mu \mathrm{g} \mathrm{L}^{-1}$ ) [33], although the LOD values were comparable to those obtained using HPLC-MS/MS (OTA, $0.5 \mathrm{ng} \mathrm{mL}^{-1}$; BPA, $0.15 \mathrm{ng} \mathrm{mL}^{-1}$ ) [34,35].

\subsubsection{Precision and Accuracy Studies}

The precision of the method was investigated by evaluating the repeatability and reproducibility of the method with three concentration levels $\left(2,20\right.$, and $40 \mathrm{ng} \mathrm{mL}^{-1}$ for OTA; 20, 60, and $150 \mathrm{ng} \mathrm{mL}^{-1}$ for PAT; 40, 400, and $800 \mathrm{ng} \mathrm{mL}^{-1}$ for HMF; 5, 40, and $80 \mathrm{ng} \mathrm{mL}^{-1}$ for BPA). Good intraday precision 
was obtained for both peak areas and retention time, with relative standard deviation values of $<4 \%$ for both peak areas and retention, as indicated in Table S1. Accuracy studies of OTA, PAT, HMF, and BPA were performed in three replicates by spiking selected drink samples with a known amount of standard at different concentration levels $\left(2,20\right.$, and $45 \mathrm{ng} \mathrm{mL}^{-1}$ for OTA; 20, 60, and $150 \mathrm{ng} \mathrm{mL}^{-1}$ for PAT; 20, 400, and $800 \mathrm{ng} \mathrm{mL}^{-1}$ for HMF; 5, 40, and $80 \mathrm{ng} \mathrm{mL}^{-1}$ for BPA). Good recovery (Table S1) was achieved for all analytes, with values ranging from $82.73 \pm 2.00 \%$ to $98.94 \pm 1.81 \%$ indicating that the improved and optimised sample preparation and HPLC-PDA/FL methods are able to provide an acceptable quantitation of the contaminants in fruit drinks.

\subsection{Application to Fruit Beverages and Drinks}

The validated HPLC-PDA/FL method was applied to examine the occurrence and levels of OTA, PAT, HMF, and BPA in the selected commercialised fruit drink samples (Table 3). Figure 3 shows typical chromatograms obtained for some of the analysed samples (dates, apple, and ambarella). In this study, most of the analysed samples were derived from tropical fruits that are native to tropical and sub-tropical regions. Tropical fruits grow in a tropical climate which is humid and warm throughout the year, hence they are more susceptible to fungal infection [6]. In the current analysis, OTA (Figure 4A) was detectable in four samples: ambarella $\left(1.55 \mathrm{ng} \mathrm{mL}^{-1}\right)$, plum $\left(1.47 \mathrm{ng} \mathrm{mL}^{-1}\right)$, dates $\left(0.98 \mathrm{ng} \mathrm{mL}^{-1}\right)$, and grape drinks $\left(0.92 \mathrm{ng} \mathrm{mL}^{-1}\right)$. The occurrence of mycotoxins in the samples indicated that the fruits used for the preparation of the drinks had been infected with fungal growth. Interestingly, ambarella and plum indicated a higher level of OTA when compared with grape drinks. Such results signified that there was an increasing tendency of OTA contaminations in fruits from warmer and tropical climates, which are usually caused by Aspergillus ochraceus, as supported by other studies conducted by Afsah-Hejri et al. and Terra et al. [6,36]. The contamination of OTA in fruits from cool climates, on the other hand, is usually associated with Penicillium verrucosum. Although the highest concentration of OTA detected was $1.55 \mathrm{ng} \mathrm{mL}^{-1}$, it is still within the permitted level suggested by the European Union Commission $\left(2 \mu \mathrm{g} \mathrm{kg}^{-1}\right)$ [8].

Table 3. Composition of ochratoxin A (OTA), patulin (PAT), 5-hydroxymethylfurfural (HMF), and bisphenol A (BPA) in the tested fruit drink samples using the optimised HPLC-PDA/FL method.

\begin{tabular}{|c|c|c|c|c|}
\hline \multirow{2}{*}{ Types of Fruit Drinks } & \multicolumn{4}{|c|}{ Average Concentration $\pm S D^{1}$} \\
\hline & $\mathrm{OTA}^{2}\left(\mathrm{ng} \mathrm{mL}^{-1}\right)$ & $\mathrm{PAT}^{3}\left(\mathrm{ng} \mathrm{mL}^{-1}\right)$ & $\mathrm{HMF}^{4}\left(\mu \mathrm{g} \mathrm{mL}^{-1}\right)$ & $\mathrm{BPA}^{5}\left(\mathrm{ng} \mathrm{mL}^{-1}\right)$ \\
\hline Ambarella & $1.55 \pm 0.08$ & $<\mathrm{LOD}^{6}$ & $18.59 \pm 0.54$ & $1.18 \pm 0.07$ \\
\hline Apple & $<\mathrm{LOD}$ & $23.80 \pm 0.82$ & $6.80 \pm 0.03$ & $<$ LOD \\
\hline Dates & $0.98 \pm 0.11$ & $<\mathrm{LOD}$ & $27.73 \pm 0.64$ & $1.02 \pm 0.01$ \\
\hline Grapes & $0.92 \pm 0.06$ & $13.06 \pm 0.50$ & $<\mathrm{LOD}$ & $<$ LOD \\
\hline Guava & $<$ LOD & $14.53 \pm 1.19$ & $12.31 \pm 0.06$ & $<\mathrm{LOD}$ \\
\hline Kiwi & $<\mathrm{LOD}$ & $93.28 \pm 0.12$ & $2.80 \pm 0.01$ & $<$ LOD \\
\hline Lychee & $<$ LOD & $<\mathrm{LOD}$ & $15.94 \pm 0.67$ & $1.54 \pm 0.06$ \\
\hline Mixed fruit & $<\mathrm{LOD}$ & $12.08 \pm 0.94$ & $<\mathrm{LOD}$ & $1.16 \pm 0.19$ \\
\hline Nutmeg & $<\mathrm{LOD}$ & $7.93 \pm 0.83$ & $25.72 \pm 2.60$ & $1.25 \pm 0.07$ \\
\hline Pineapple & $<\mathrm{LOD}$ & $47.78 \pm 1.79$ & $17.04 \pm 0.49$ & $<$ LOD \\
\hline Plum 1 & $1.47 \pm 0.04$ & $<\mathrm{LOD}$ & $11.81 \pm 0.66$ & $<\mathrm{LOD}$ \\
\hline Plum 2 & $<$ LOD & $<\mathrm{LOD}$ & $<\mathrm{LOD}$ & $8.59 \pm 0.45$ \\
\hline Roselle & $<\mathrm{LOD}$ & $36.72 \pm 0.46$ & $<\mathrm{LOD}$ & $<$ LOD \\
\hline Soursop & $<\mathrm{LOD}$ & $<\mathrm{LOD}$ & $0.13 \pm 0.01$ & $<\mathrm{LOD}$ \\
\hline
\end{tabular}

${ }^{1}$ SD: standard deviation. ${ }^{2}$ OTA: ochratoxin A. ${ }^{3}$ PAT: patulin. ${ }^{4}$ HMF: 5-hydroxymethylfurfural. ${ }^{5}$ BPA: bisphenol A. ${ }^{6}<$ LOD: below limit of detection. 

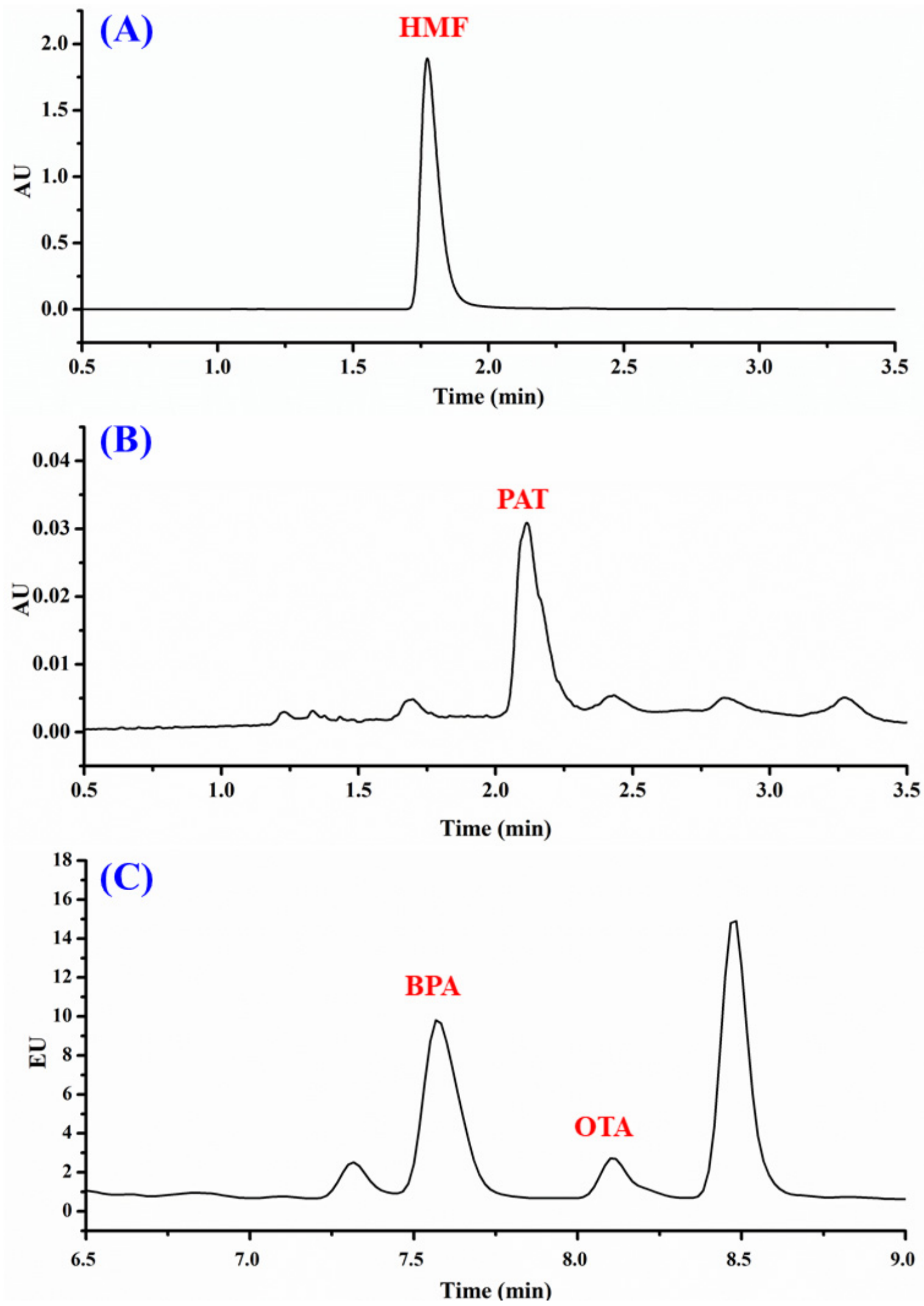

Figure 3. HPLC-PDA/FL analysis of fruit drink samples: (A) dates drink showing detected 5-hydroxymethylfurfural (HMF); (B) apple drink showing detected patulin (PAT); (C) ambarella drink showing detected bisphenol A (BPA) and ochratoxin A (OTA). 
For PAT, the current results (Table 3) indicated its occurrence at a different level in $57 \%$ of the analysed fruit drinks. In addition to the apple drink samples, the contamination of PAT by microfungi producing PAT was also observed at much higher levels in other fruit drinks. The highest PAT content was found in kiwi drink samples $\left(93.28 \mathrm{ng} \mathrm{mL}^{-1}\right)$, then pineapple drink samples (47.78 $\left.\mathrm{ng} \mathrm{mL}^{-1}\right)$, followed by roselle $\left(36.72 \mathrm{ng} \mathrm{mL}^{-1}\right)$ and apple $\left(23.8 \mathrm{ng} \mathrm{mL}^{-1}\right)$ drink samples. The high concentration of PAT found in the kiwi drink is in good agreement with a similar study which reported 45.102-268.88 $\mu \mathrm{g} \mathrm{mL}^{-1}$ of PAT in kiwi juice samples from different cultivars [37]. Surveys on the occurrence of PAT contamination in food mostly focus on apple-based products associated with the apple-rotting fungus Penicillium expansum; however, recently PAT was reported in various fruit commodities around the world [13,15]. Recent findings by Iqbal et al. (2018) indicated that $54.5 \%$ of the tested pineapple samples exceeded the permitted EU level $\left(50 \mu \mathrm{g} \mathrm{kg}^{-1}\right)$, with highest PAT content up to $460.3 \mu \mathrm{g} \mathrm{kg}^{-1}$ [13]. In order to mitigate the OTA and PAT contaminations, the selection of infected fruits must be strengthened, and cleaning must be improved prior to processing, as the applied thermal treatment cannot effectively remove the mycotoxins $[11,12]$.

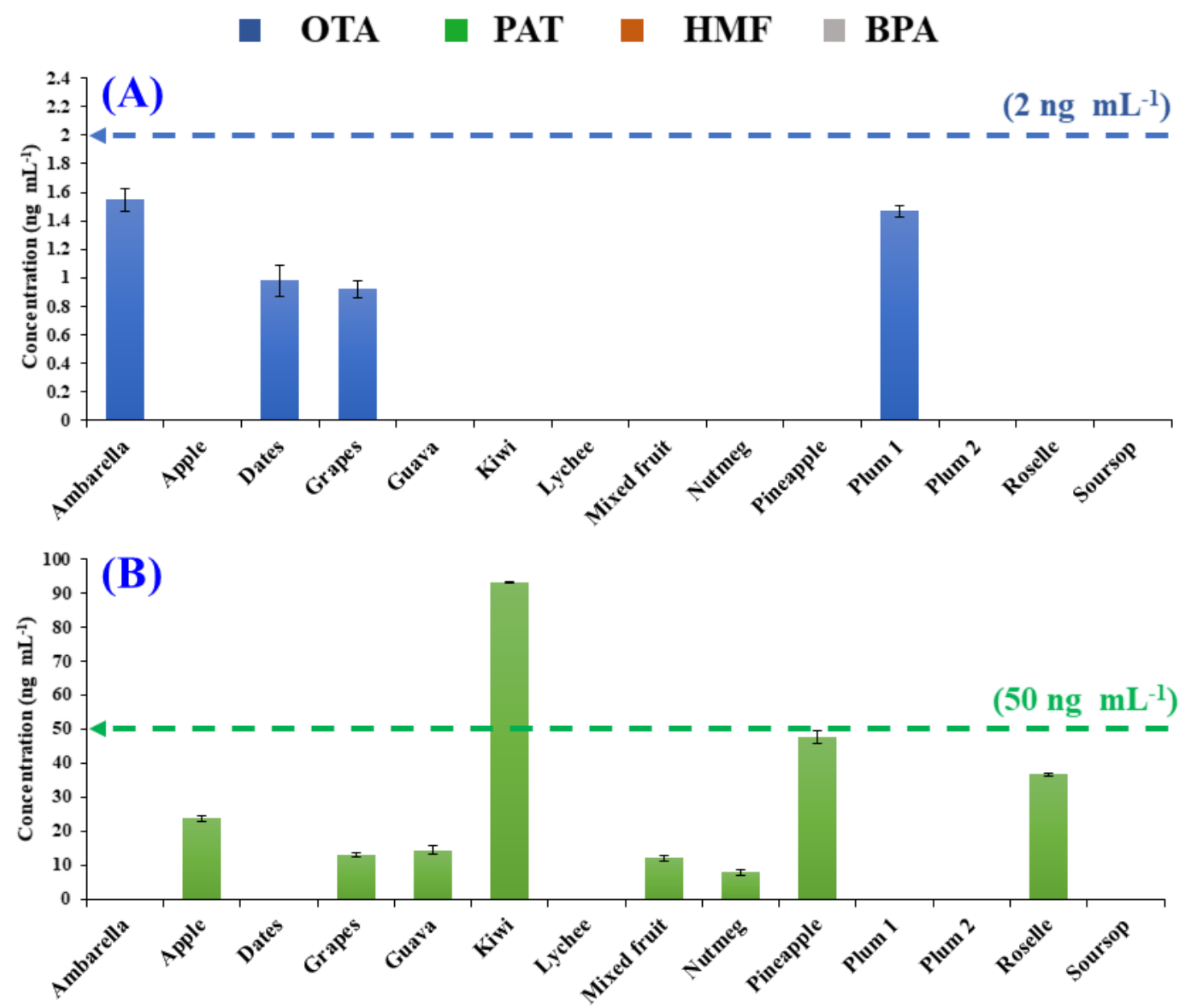

Figure 4. Cont. 

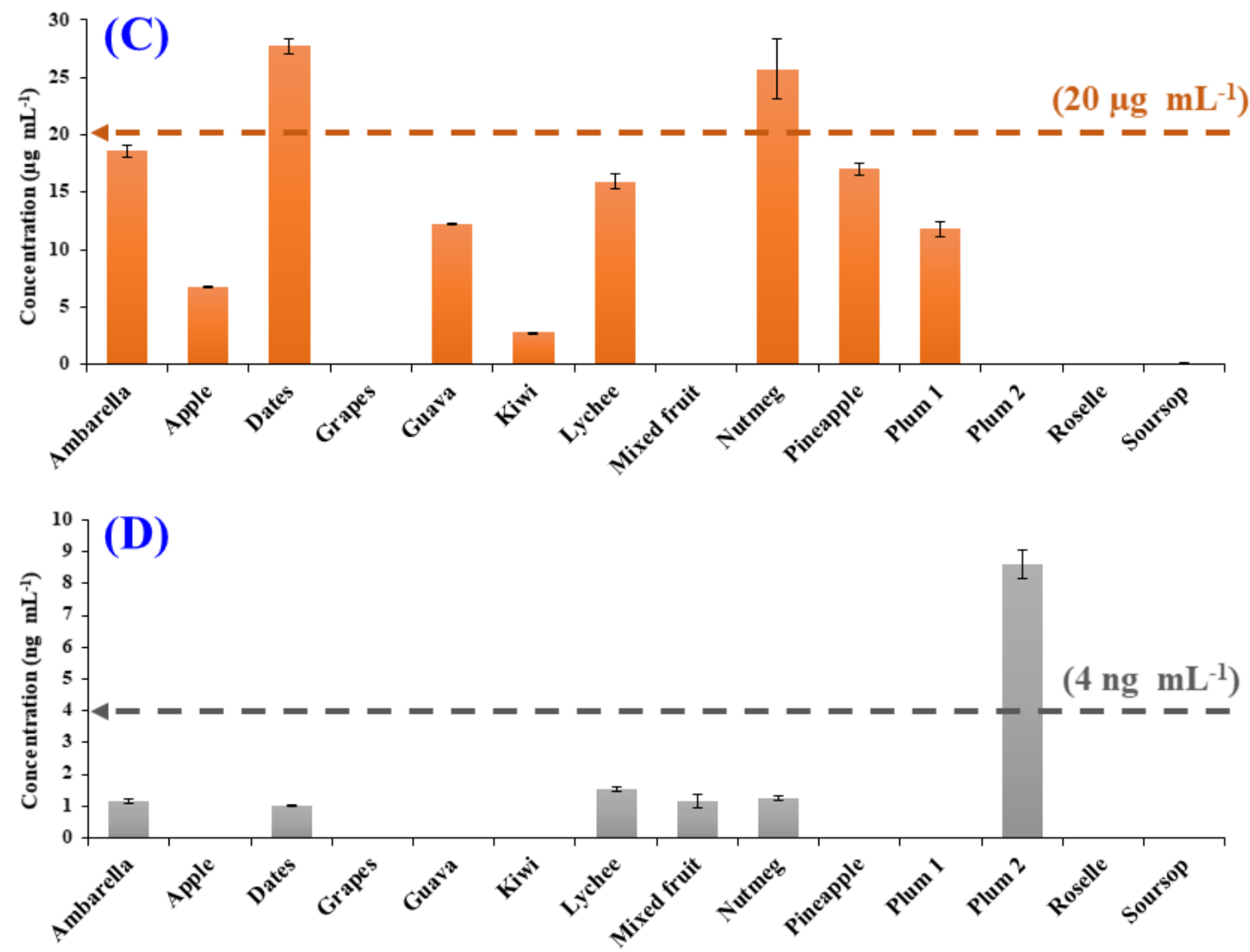

Types of fruit drinks

Figure 4. Graphical presentations of the positive fruit drink samples containing (A) ochratoxin A (OTA); (B) patulin (PAT); (C) 5-hydroxymethyfurfural (HMF); (D) bisphenol A (BPA). The coloured dashed lines correspond to the maximum permitted levels of the stated compounds in fruit juices established by the European Union (EU; for OTA, PAT, HMF) and the European Food Safety Authority (EFSA; for BPA).

For HMF, 10 out of 14 samples tested positive, with concentrations ranging from $0.13-27.73 \mu \mathrm{gL}^{-1}$. The variation in the HMF contents may suggest that the fruit drink samples had undergone thermal treatment to improve sensory properties and extend their shelf life. In particular, dates $\left(27.73 \mu \mathrm{g} \mathrm{mL}^{-1}\right)$ and nutmeg $\left(25.72 \mu \mathrm{g} \mathrm{mL}^{-1}\right)$ samples surpassed the EU legal limit of $20 \mathrm{mg} \mathrm{kg}^{-1}$ (Figure 4C). Dates are a tropical fruit that are rich in nutrients and have high sugar content, mainly glucose and fructose. The presence of reducing sugar in an acidic environment could accelerate the generation of HMF via Maillard reaction $[17,27]$. Previous studies have reported the presence of HMF in dates syrup ranging from $42.8-84.2 \mathrm{mg} / 100 \mathrm{~g}$ dry weight [38], and approximately $1000 \mathrm{mg} / \mathrm{kg}$ were detected in dried dates [39].

BPA levels in the examined fruit drinks samples are given in Table 3, with average concentrations between 1.02-8.59 $\mathrm{ng} \mathrm{mL}^{-1}$. Five of the positive samples showed lower BPA content than the maximum permitted EFSA limit $\left(4 \mu \mathrm{g} \mathrm{kg}^{-1}\right)$. The BPA chromatogram of the ambarella drink is illustrated in Figure 3C. The obtained values have good agreement in comparison with a previous study by Geens et al., which reported that the average BPA concentrations in beverages and canned foods were $1 \mathrm{ng} \mathrm{mL}^{-1}$ and $40.3 \mathrm{ng} \mathrm{g}^{-1}$, respectively [40]. In another study, the levels of BPA in juice samples were significantly higher, ranging from $40.27-82.55 \mu \mathrm{g} \mathrm{kg}^{-1}$ [30]. Nevertheless, the migration of BPA into food products varied depending on the food packaging type, as higher BPA migration was detected in canned food products in comparison to other types of food packaging [30,40-42]. Zhang et al. conducted a study on BPA prevalence in the environment by examining the presence of 
BPA in urine samples in several Asian countries. The average BPA detected in urine samples from Malaysia was $1.06 \mathrm{ng} \mathrm{mL}^{-1}$, whereby the daily BPA exposure of Malaysians was estimated to be 0.08-22.9 $\mu \mathrm{g} \mathrm{day}^{-1}$ [25]. Thus, the obtained results are in accordance with previous investigations.

Although the levels of detected contaminants were mostly within the legal limits established by the accredited bodies (Figure 4), continuous monitoring of such contaminants in fruit drinks is important and necessary in order to safeguard consumers and protect public health. The current reported multi-contaminants analysis approach will be especially useful for routine quality control or monitoring of such contaminants in fruit juices and drinks. In the longer run, good agricultural and processing practices need to be strengthened to avoid fungal growth and mitigate the occurrence of these contaminants in fruit drinks.

\section{Conclusions}

This study described simple, rapid, and cost-effective preparation steps with HPLC-UV/FL detection to quantify OTA, PAT, HMF, and BPA in various fruit drinks. Using the optimised chromatographic conditions, the simultaneous separation of the four contaminants was achieved in $<9 \mathrm{~min}$. Validation data demonstrated good linearity, recoveries, retention, and response area reproducibility. The method was successfully applied for the determination of OTA, PAT, HMF, and BPA in various fruit drinks and concentrates. All the analysed samples indicated the presence of OTA (0.92-1.55 $\left.\mathrm{ng} \mathrm{mL}^{-1}\right)$, PAT (7.93-93.28 $\left.\mathrm{ng} \mathrm{mL}^{-1}\right), \operatorname{HMF}\left(0.13-27.73 \mu \mathrm{g} \mathrm{mL}^{-1}\right)$, and BPA (1.02-8.59 $\left.\mathrm{ng} \mathrm{mL}^{-1}\right)$ at different concentration levels, either separately or in combinations. These observations signify the need for routine quality control of the commercialised fruit juices and drinks to confirm their quality and safety. The proposed multi-contaminants analysis approach provides considerable advantages in terms of cost, simplicity, analysis time, and sensitivity, and can be readily utilised in most food analytical laboratories for the routine monitoring and control of these contaminants.

Supplementary Materials: The following are available online at http://www.mdpi.com/2304-8158/9/11/1633/s1: Table S1: Intraday precision and accuracy of the developed HPLC-PDA/FL method.

Author Contributions: Y.F.W. and N.R.A.M. conceived and designed the experiments; N.H.H. and N.R.A.M. conducted the experiments; N.H.H. and N.R.A.M. analysed the data; N.H.H., H.I.A.A.O., N.R.A.M., M.Z., B.S., and Y.F.W. wrote the manuscript; Y.F.W. acquired funding. All authors have read and agreed to the published version of the manuscript.

Funding: This research was funded by Universiti Sains Malaysia through Short Term Research Grant (203.PKIMIA. 6315191).

Acknowledgments: Y.F.W. acknowledges the financial support provided by Universiti Sains Malaysia. The authors would like to thank Noorfatimah Binti Yahaya for provision of the BPA standard used in this study.

Conflicts of Interest: The authors declare no conflict of interest.

\section{References}

1. Fruit and Vegetable Juices Global Market Trajectory \& Analytics; Global Industry Analysts, Inc. Available online: https://www.researchandmarkets.com/reports/338669/fruit_and_vegetable_juices_global_market (accessed on 13 July 2020).

2. National Institute of Environmental Health Sciences. Environmental Agents. Available online: https: //www.niehs.nih.gov/health/topics/agents/index.cfm (accessed on 13 July 2020).

3. Jard, G.; Liboz, T.; Mathieu, F.; Guyonvarc'h, A.; Lebrihi, A. Review of mycotoxin reduction in food and feed: From prevention in the field to detoxification by adsorption or transformation. Food Addit. Contam. Part A 2011, 28, 1590-1609. [CrossRef] [PubMed]

4. Karlovsky, P.; Suman, M.; Berthiller, F.; De Meester, J.; Eisenbrand, G.; Perrin, I.; Oswald, I.P.; Speijers, G.; Chiodini, A.; Recker, T. Impact of food processing and detoxification treatments on mycotoxin contamination. Mycotoxin Res. 2016, 32, 179-205. [CrossRef]

5. Bui-Klimke, T.R.; Wu, F. Ochratoxin A and human health risk: A review of the evidence. Crit. Rev. Food Sci. Nutr. 2015, 55, 1860-1869. [CrossRef] 
6. Afsah-Hejri, L.; Jinap, S.; Hajeb, P.; Radu, S.; Shakibazadeh, S. A review on mycotoxins in food and feed: Malaysia case study. Compr. Rev. Food Sci. Food Saf. 2013, 12, 629-651. [CrossRef]

7. International Agency for Research on Cancer. IARC Monograph on the Evaluation of Carcinogenic Risks to Humans; IARC: Lyon, France, 1993; p. 489.

8. EC (European Commission). Commission regulation (EC) no 1881/2006 of 19 December 2006 setting maximum levels for certain contaminants in foodstuffs. Off. J. Eur. Union 2006, 364, 324-365.

9. Joint FAO/WHO Committee on Food Additives (JECFA). Evaluation of Certain Food Additives and Contaminants (Sixty-Eighth Report) of the Joint FAO/WHO Expert Committee on Food Additives; World Health Organization: Geneva, Switzerland, 2007.

10. Zouaoui, N.; Sbaii, N.; Bacha, H.; Abid-Essefi, S. Occurrence of patulin in various fruit juice marketed in Tunisia. Food Control 2015, 51, 356-360. [CrossRef]

11. Marín, S.; Mateo, E.M.; Sanchis, V.; Valle-Algarra, F.M.; Ramos, A.J.; Jiménez, M. Patulin contamination in fruit derivatives, including baby food, from the Spanish market. Food Chem. 2011, 124, 563-568. [CrossRef]

12. Oteiza, J.M.; Khaneghah, A.M.; Campagnollo, F.B.; Granato, D.; Mahmoudi, M.R.; Sant'Ana, A.S.; Gianuzzi, L. Influence of production on the presence of patulin and ochratoxin A in fruit juices and wines of Argentina. LWT 2017, 80, 200-207. [CrossRef]

13. Iqbal, S.Z.; Malik, S.; Asi, M.R.; Selamat, J.; Malik, N. Natural occurrence of patulin in different fruits, juices and smoothies and evaluation of dietary intake in Punjab, Pakistan. Food Control. 2018, 84, 370-374. [CrossRef]

14. Sadok, I.; Stachniuk, A.; Staniszewska, M. Developments in the monitoring of patulin in fruits using liquid chromatography: An overview. Food Anal. Method. 2019, 12, 76-93. [CrossRef]

15. Vidal, A.; Ouhibi, S.; Ghali, R.; Hedhili, A.; De Saeger, S.; De Boevre, M. The mycotoxin patulin: An updated short review on occurrence, toxicity and analytical challenges. Food Chem. Toxicol. 2019, 129, 249-256. [CrossRef] [PubMed]

16. Joint FAO/WHO Committee on Food Additives (JECFA). Evaluations of Certain Food Additives and Contaminants; World Health Organization: Geneva, Switzerland, 1995; Series 859.

17. Abraham, K.; Gürtler, R.; Berg, K.; Heinemeyer, G.; Lampen, A.; Appel, K.E. Toxicology and risk assessment of 5-Hydroxymethylfurfural in food. Mol. Nutr. Food Res. 2011, 55, 667-678. [CrossRef]

18. Czerwonka, M.; Opiłka, J.; Tokarz, A. Evaluation of 5-hydroxymethylfurfural content in non-alcoholic drinks. Eur. Food Res. Technol. 2018, 244, 11-18. [CrossRef]

19. Gaspar, E.M.; Lucena, A.F. Improved HPLC methodology for food control-furfurals and patulin as markers of quality. Food Chem. 2009, 114, 1576-1582. [CrossRef]

20. EC (European Commission). Commission regulation (EC) no 1881/2006. Directive 2001/110/EC. Off. J. Eur. Union 2001, 47-52.

21. Careghini, A.; Mastorgio, A.F.; Saponaro, S.; Sezenna, E. Bisphenol A, nonylphenols, benzophenones, and benzotriazoles in soils, groundwater, surface water, sediments, and food: A review. Environ. Sci. Pollut. Res. 2015, 22, 5711-5741. [CrossRef] [PubMed]

22. Baluka, S.A.; Rumbeiha, W.K. Bisphenol A and food safety: Lessons from developed to developing countries. Food Chem. Toxicol. 2016, 92, 58-63. [CrossRef]

23. Rubin, B.S. Bisphenol A: An endocrine disruptor with widespread exposure and multiple effects. J. Steroid Biochem. Mol. Biol. 2011, 127, 27-34. [CrossRef]

24. European Food Safety Authority (EFSA). Scientific Opinion on the risks to public health related to the presence of bisphenol A in foodstuffs: EFSA Panel on Food Contact Materials, Enzymes, Flavorings and Processing Aids. EFSA J. 2015, 13, 3978. [CrossRef]

25. Zhang, Z.; Alomirah, H.; Cho, H.-S.; Li, Y.-F.; Liao, C.; Minh, T.B.; Mohd, M.A.; Nakata, H.; Ren, N.; Kannan, K. Urinary bisphenol A concentrations and their implications for human exposure in several Asian countries. Environ. Sci. Technol. 2011, 45, 7044-7050. [CrossRef]

26. Karami-Osboo, R.; Miri, R.; Javidnia, K.; Kobarfard, F.; AliAbadi, M.H.S.; Maham, M. A validated dispersive liquid-liquid microextraction method for extraction of ochratoxin A from raisin samples. J. Food Sci. Tech. 2015, 52, 2440-2445. [CrossRef]

27. Lee, T.P.; Sakai, R.; Manaf, N.A.; Rodhi, A.M.; Saad, B. High performance liquid chromatography method for the determination of patulin and 5-hydroxymethylfurfural in fruit juices marketed in Malaysia. Food Control. 2014, 38, 142-149. [CrossRef] 
28. Mignot, M.; Tchapla, A.; Mercier, O.; Couvrat, N.; Tisse, S.; Cardinael, P.; Peulon-Agasse, V. High-density octadecyl chemically bonded core-shell silica phases for HPLC: Comparison of microwave-assisted and classical synthetic routes, structural characterization and chromatographic evaluation. Chromatographia 2014, 77, 1577-1588. [CrossRef]

29. Sowa, I.; Zielińska, S.; Sawicki, J.; Bogucka-Kocka, A.; Staniak, M.; Bartusiak-Szcześniak, E.; Podolska-Fajks, M.; Kocjan, R.; Wójciak-Kosior, M. Systematic evaluation of chromatographic parameters for isoquinoline alkaloids on XB-C18 core-shell column using different mobile phase compositions. J. Anal. Methods. Chem. 2018, 3,1-8. [CrossRef]

30. Sungur, Ş.; Köroğlu, M.; Özkan, A. Determinatıon of bisphenol a migrating from canned food and beverages in markets. Food Chem. 2014, 142, 87-91. [CrossRef]

31. Lee, T.P.; Saad, B.; Salleh, B.; Mat, I. Micro-solid phase extraction of ochratoxin A, and its determination in urine using capillary electrophoresis. Microchim. Acta 2013, 180, 1149-1156. [CrossRef]

32. Gallart-Ayala, H.; Núñez, O.; Moyano, E.; Galceran, M.T. Field-amplified sample injection-micellar electrokinetic capillary chromatography for the analysis of bisphenol A, bisphenol F, and their diglycidyl ethers and derivatives in canned soft drinks. Electrophoresis 2010, 31, 1550-1559. [CrossRef] [PubMed]

33. Bationo, R.; Jordana, F.; Boileau, M.-J.; Colat-Parros, J. Release of monomers from orthodontic adhesives. Am. J. Orthod. Dentofac. 2016, 150, 491-498. [CrossRef]

34. Al-Taher, F.; Banaszewski, K.; Jackson, L.; Zweigenbaum, J.; Ryu, D.; Cappozzo, J. Rapid method for the determination of multiple mycotoxins in wines and beers by LC-MS/MS using a stable isotope dilution assay. J. Agric. Food Chem. 2013, 61, 2378-2384. [CrossRef]

35. Gallo, P.; Di Marco Pisciottano, I.; Fattore, M.; Rimoli, M.G.; Seccia, S.; Albrizio, S. A method to determine $\mathrm{BPA}, \mathrm{BPB}$, and BPF levels in fruit juices by liquid chromatography coupled to tandem mass spectrometry. Food Addit. Contam. Part A 2019, 36, 1871-1881. [CrossRef] [PubMed]

36. Terra, M.F.; Prado, G.; Pereira, G.E.; Ematné, H.J.; Batista, L.R. Detection of ochratoxin A in tropical wine and grape juice from Brazil. J. Sci. Food Agric. 2013, 93, 890-894. [CrossRef] [PubMed]

37. Wang, Y.; Shan, T.; Yuan, Y.; Zhang, Z.; Guo, C.; Yue, T. Evaluation of Penicillium expansum for growth, patulin accumulation, nonvolatile compounds and volatile profile in kiwi juices of different cultivars. Food Chem. 2017, 228, 211-218. [CrossRef]

38. Derouich, M.; Meziani, R.; Bourkhis, B.; Filali-Zegzouti, Y.; Chakib, A. Nutritional, mineral and organic acid composition of syrups produced from six Moroccan date fruit (Phoenix dactylifera L.) varieties. J. Food Compos. Anal. 2020, 93, 103591.

39. Shapla, U.M.; Solayman, M.; Alam, N.; Khalil, M.I.; Gan, S.H. 5-Hydroxymethylfurfural (HMF) levels in honey and other food products: Effects on bees and human health. Chem. Cent. J. 2018, 12, 35-52. [CrossRef]

40. Geens, T.; Apelbaum, T.Z.; Goeyens, L.; Neels, H.; Covaci, A. Intake of bisphenol A from canned beverages and foods on the Belgian market. Food Addit. Contam. 2010, 27, 1627-1637. [CrossRef]

41. Noonan, G.O.; Ackerman, L.K.; Begley, T.H. Concentration of bisphenol A in highly consumed canned foods on the US market. J. Agric. Food Chem. 2011, 59, 7178-7185. [CrossRef]

42. Lorber, M.; Schecter, A.; Paepke, O.; Shropshire, W.; Christensen, K.; Birnbaum, L. Exposure assessment of adult intake of bisphenol A (BPA) with emphasis on canned food dietary exposures. Environ. Int. 2015, 77, 55-62. [CrossRef] [PubMed]

Publisher's Note: MDPI stays neutral with regard to jurisdictional claims in published maps and institutional affiliations.

(C) 2020 by the authors. Licensee MDPI, Basel, Switzerland. This article is an open access article distributed under the terms and conditions of the Creative Commons Attribution (CC BY) license (http://creativecommons.org/licenses/by/4.0/). 